\title{
Prospects for colorectal cancer prevention targeting intestinal microbiome
}

\author{
Tadashi Ohara, MD, PhD \\ Department of Gastroenterology, Kitashinagawa Third Hospital, Kohno Clinical Medicine Research Institute, Japan
}

It has been reported that a so-called clean colon procedure, in which all precancerous lesions, colorectal tubular adenomas / colorectal tubulovillous adenomas, are endoscopically resection treatment is extremely useful for preventing colorectal carcinogenesis and death from colorectal cancer [1-4]. The effectiveness of chemopreventive measures to take the antidiabetic drugs metformin and low-dose aspirin has also been reported [5-7]. Recently, there have been reports suggesting the involvement of intestinal microorganisms such as Fusobacterium nucleatum (F. nucleatum) in colorectal carcinogenesis [8-13], and there is a possibility that a strategy targeting intestinal microorganisms will be taken as future methods for preventing colorectal carcinogenesis. This review describes the prospects for new strategies on colorectal carcinogenesis prevention targeting intestinal microbiome such as F. nucleatum.

Currently, there are no clinical research reports on intestinal microbes and prevention of colorectal carcinogenesis in human, but there are reports in animal models. When the antibacterial drug metronidazole was administered to the F. nucleatum-infected group and the non-infected group in mouse colorectal cancer model, the tumor size was smaller in the F. nucleatum-infected group and the tumor size did not change in the non-infected group. In addition, $F$. nucleatum in colorectal cancer tissue was significantly decreased in the metronidazole-administered group, and the uptake of BrdU, which is one of the cell proliferation markers, into cell was decreased in the metronidazole-administered group, and the cell proliferation was also suppressed [14]. These results suggest that F. nucleatum eradication may suppress the growth of colorectal cancer, and it is interesting to see if the same results can be obtained in human.

The next part is a commentary on the preventive effects of probiotics and prebiotics for colorectal carcinogenesis. Probiotics and prebiotics have been collectively called or functional lactic acid bacteria foods or functional foods in recent years. Prebiotics is a concept proposed by Gibson et al. $[15,16]$. which is an indigestible food ingredient that beneficially affects specific microbes living in the large intestine and improves the intestinal gut flora to a healthy state, and oligosaccharide is a typical example [17]. Furthermore, Functional foods which combine probiotics and prebiotics are called symbiotics.

The following papers are representative reports on preventive mechanisms of colorectal carcinogenesis in probiotics and prebiotics.

The first report is that probiotics bind to the causative agent of carcinogenesis and suppress gene mutations. This is the function of probiotics itself, as below; Streptococcus cremoris Z-25, Lactobacillus acidophilus IFO 13951 and Bifidobacterium bifidum IF014252 bind to Trip-P1 (3-amino-1,4-dymethyl-5H-pyrido[4,3-b]-indole), GR-1 (2-Amino-6-mechyldipyrido-[12-a:3',2'-d]-imidazole), Phe-P-1 (2-amino-5-phyenylpyridine), IQ (2-amino-3-metylimidazo[4,5-f]- quinoline), MeIQ (2-amino-3,4-dimethylimidazo[4,5-f]-quinoline), MeIQx (2-amino-3,8-dimethylimidazo[4],5-f]-quinoxaline) and other heterocyclic amines (HCA). HCA is a carcinogen that is mainly found in charred meat and fish. In addition, probiotics have also been reported to have the effect of inhibiting the carcinogenic precursors into carcinogens [18]. However, the details of binding mechanism to HCA and the details of conversion mechanism carcinogenic precursors into carcinogens have not yet been clarified.

The second reports are the antitumor effect of the intestinal $\mathrm{pH}$ lowering effect of the production of short-chain fatty acids. Gut flora, including probiotics, and prebiotics lower the $\mathrm{pH}$ in the intestine by producing short-chain fatty acids such as butyric acid, propionic acid, and acetic acid. By reducing the number of intestinal microbes that become pathogens by lowering the intestinal $\mathrm{pH}$, inflammation is suppressed and the homeostasis of the intestinal environment is maintained $[19,20]$. However, the intestinal environment such as the ascending colon and the transverse colon is under strong acidity, and colorectal cancer is observed even under strong acidity. Therefore, this theory is not convincing.

The third reports are on the suppression of inflammation and carcinogenesis by activating the host immunity of probiotics. This is a report that probiotics indirectly exert antitumor effects by maturing dendritic cells and activating natural killer cells (NK cells) [21]. For example, butyric acid not only lowers the $\mathrm{pH}$ of the intestinal lumen, but also nourishes the mucosal tissue of the large intestine and promotes histone acetylation by inhibiting the deacetylation of histone as a DNAbinding protein, at the molecular level. This promotes the expression of Foxp3, promotes the differentiation of regulatory $\mathrm{T}$ cells ( $\mathrm{T}$ reg) from naïve $\mathrm{T}$ cells and suppresses inflammation, and induces apoptosis to suppress carcinogenesis [22]. Propionic acid and acetic acid have also been reported to induce apoptosis in vitro [23]. On the other hand, it has also been reported that Treg is also involved in carcinogenesis [24-28]. It has been reported that the apoptosis or tumorigenicitypromoting effect of Treg is determined by the amount of butyric acid produced $[29,30]$, but the detail has not been clarified.

The fourth is our reports. Our reports analyze the mechanism of antitumor action of short-chain fatty acids produced by probiotics and prebiotics. We confirmed by analysis of the intestinal microbiome that

${ }^{*}$ Correspondence to: Tadashi Ohara, $\mathrm{MD}, \mathrm{PhD}$, Department of Gastroenterology, Kitashinagawa Third Hospital, Kohno Clinical Medicine Research Institute, 3-3-7 Kitashinagawa, Shinagawa, Tokyo 140-0001, Japan, Tel: +81-3-34741831, Fax: +81-5461-3740, E-mail: t.ohara@kcmi.or.jp

Received: January 03, 2021; Accepted: January 26, 2021; Published: January 29, 2021 
feeding healthy volunteers with probiotics (Bifidobacterium longum: BB536) and prebiotics (Oligosaccharides) increased the production of short-chain fatty acids such as butyric acid, which has antitumor effects. Therefore, we added butyric acid, isobutyric acid, and acetic acid adjusted to 11 levels of concentration to human colorectal cancer cells (DLD-1 cells, WirDr cells) and cultured them to examine the proliferative ability of colorectal cancer cells. The results showed that the cell proliferation ability of colon cancer cells was significantly suppressed by the addition of the above-mentioned short-chain fatty acids and butyric acid had the strongest cell proliferation-suppressing ability among the short-chain fatty acids [31]. Then, we investigated the mechanism of antitumor action of short-chain fatty acids in cultured cells by DNA microarray analysis. In the analysis of the mechanism by DNA microarray, the expression of genes involved in the cell proliferation systems such as cell rotations and DNA replications were strongly suppressed [32]. It was new findings that short-chain fatty acids did not affect the expression of cancer-related genes which were previously considered essential for carcinogenesis and strongly suppressed the expression of genes involved in the cell proliferation. Our reports are drawing attention as a new mechanism on colorectal carcinogenesis suppression of probiotics and prebiotics.

Currently, there are still little evidence for the suppressive effects of probiotics and prebiotics on colorectal cancer, and they have not been used in clinical practice is the detail on suppressive mechanisms of probiotics is elucidated in the future, it should more likely to be used in clinical treatments. We look forward to the further developments of research in this field.

\section{References}

1. East JE, Atkin WS, Bateman AC, Clark SK, Dolwani S, et al. (2017) British society of Gastroenterology position statement on serrated polyps in the colon and rectum. Gut 66: 1181-1196. [Crossref]

2. Chang K, Taggart MW, Reyes-Uribe L, Borras E, Riquelme E, et al. (2018) Immune profiling of premalignant lesions in patients with Lynch syndrome. JAMA Oncol 4: 1085-1092. [Crossref]

3. IJspeert JE, Medema JP, Dekker E (2015) Colorectal neoplasia pathways: state of the art. Gastrointest Endosc Clin N Am 25: 169-182. [Crossref]

4. Sangha S, Yao M, Wolfe MM (2005) Non-steroidal anti-inflammatory drugs and colorectal cancer prevention. Postgrad Med J 81: 223-227. [Crossref]

5. Higurashi T, Hosono K, Takahashi H, Komiya Y, Umezawa S, et al. (2016) Metformin for chemoprevention of metachronous colorectal adenoma or polyps in postpolypectomy patients without diabetes: a multicentre double-blind, placebo-controlled, randomized phase 3 trial. Lancet Oncol 17: 475-483. [Crossref]

6. Rothwell PM, Wilson M, Elwin CE, Norrving B, Algra A, et al. (2010) Long-term effect of aspirin on colorectal cancer incidence and mortality: 20-year follow-up of five randomized trials. Lancet 376: 1741-1750. [Crossref]

7. Umezawa S, Higurashi T, Komiya Y, Arimoto J, Horita N, et al. (2019) Chemoprevention of colorectal cancer: Past, present, and future. Cancer Sci 110: 3018-3026. [Crossref]

8. Rubinstein MR, Wane X, Liu W, Hao Y, Cai G, et al. (2013) Fusobacterium nucleatum promotes colorectal carcinogenesis by modulating E-cadherin/ $\beta$-catenin signaling via its Fad A adhesion. Cell Host Microbe 14: 195-206. [Crossref]

9. Kostic AD, Chun E, Robertson L, Glickman JN, Gallini CA, et al. (2013) Fusobacterium nucleatum potentiates intestinal tumorigenesis and modulates the tumor-immune microenvironment. Cell Host Microbe 14: 207-215. [Crossref]

10. Shi C, Yang Y, Xia Y, Okugawa Y, Yane J, et al. (2016) Novel evidence for an oncogenic role of micro-RNA-21 in colitis-associated colorectal cancer. GUT 65: 1470-1481. [Crossref]

11. Yang Y, Weng W, Peng J, Hong L, Yang L, et al. (2017) Fusobacterium nucleatum increases proliferation of colorectal cancer cells and tumor development in mice by activating Toll-like receptor 4 signaling to Nuclear Factor- $\mathrm{kB}$, and up-regulating expression of micro-RNA-21. Gastroenterol 152: 851-866. [Crossref]

12. Chen Y, Peng Y, Yu J, Chen T, Wu Y, et al. (2017) Invasive Fusobacterium nucleatum activates beta-catenin signaling in colorectal cancer via a TLR4/P-PARK1 cascade. Oncotarget 8: 31802-31814. [Crossref]
13. Woelber JP, Tennert C (2020) Diet and periodontal disease. Monogr Oral Sci 28: 125 133. [Crossref]

14. Bullman S, Pedamallu CS, Sicnska E, Clancy TE, Zhang X, et al. (2017) Analysis of Fusobacterium persistence and antibiotic response in colorectal cancer. Science 358: 1443-1448. [Crossref]

15. Gibson GR, Hutkins R, Sanders ME, Prescott SL, Reimer RA, et al. (2017) Expert consensus document: The International Scientific Association for Probiotics and Prebiotics (ISAPP) consensus statement on the definition and scope of prebiotics. Nat Rev Gastroenterol Hepatol 14: 491-502. [Crossref]

16. Wang X, Gibson GR, Sailer M, Theis S, Rastall RA (2020) Prebiotics Inhibit Proteolysis by Gut Bacteria in a Host Diet-Dependent Manner: a Three-Stage Continuous In Vitro Gut Model Experiment. Appl Environ Microbiol 86: e02730-19. [Crossref]

17. Gibson GR, Roberfroid MB (1995) Dietary modulation of the human colonic microbiota: introducing the concept of the probiotics. J Nutr 125: 1401-1412. [Crossref]

18. Zhang XB, Ohta Y (1991) Binding of mutagens by fractions of the cell wall skeleton of lactic acid bacteria on the mutagens. J Daily Sci 74: 1477-1481. [Crossref]

19. Csordas A (1996) Butyrate, aspirin and colorectal cancer. Eur J Cancer Prev 5: 221231. [Crossref]

20. Jacobasch G, Dongowski G, Florian S, Müller-Schmehl K, Raab B, et al. (2008) Pectin does not inhibit intestinal carcinogenesis in APC-deficient Min/+ mice. J Agric Food Chem 56: 1501-1510. [Crossref]

21. Roman M, Ambalam P, Kondepudi KK, Pithva S, Kothari C, et al. (2013) Potential of probiotics, prebiotics and synbiotics for management of colorectal cancer. Gut Microbes 4: 181-192. [Crossref]

22. Medina V, Edmonds B, Young GP, James R, Appleton S, et al. (1997) Introduction of caspase-3 protease activity and apoptosis and synergy with a mitochondrial/cytochrome c-dependent pathway. Cancer Res 57: 3697-3707. [Crossref]

23. 23. Lan G, Belzacq AS, Haouzi D, Rouault A, Metivier D, et al. (2002) Propionibacteria induce apoptosis of colorectal carcinoma cells via short -chain fatty acids acting on mitochondria. Cell Death Differ 9: 179-188.

24. Sui H, Zhang L, Gu K, Chai N, Ji Q, et al. (2020) YYFZBJS ameliorates colorectal cancer progression in Apc (Min/+) mice by remodeling gut microbiota and inhibiting regulatory T-cell generation. Cell Commun Signal 18: 113. [Crossref]

25. François S, Usunier B, Forgue-Lafitte ME, L'Homme B, Benderitter M, et al. (2019) Mesenchymal Stem Cell Administration Attenuates Colon Cancer Progression by Modulating the Immune Component within the Colorectal Tumor Microenvironment. Stem Cells Transl Med 8: 285-300. [Crossref]

26. Nguyen AV, Wu YY, Liu Q, Wang D, Nguyen S, et al. (2013) STAT3 in epithelial cells regulates inflammation and tumor progression to malignant state in colon. Neoplasia $15: 998-1008$. [Crossref]

27. Karagiannidis I, Jerman SJ, Jacenik D, Phinney BB, Yao R, et al. (2020) G-CSF and G-CSFR Modulate CD4 and CD8 T Cell Responses to Promote Colon Tumor Growth and Are Potential Therapeutic Targets. Front Immunol 11: 1885. [Crossref]

28. Chen X, Takemoto Y, Deng H, Middelhoff M, Friedman RA, et al. (2017) Histidine decarboxylase (HDC)-expressing granulocytic myeloid cells induce and recruit Foxp3 regulatory T cells in murine colon cancer. Oncoimmunology 6: e1290034. [Crossref]

29. Coutzac C, Jouniaux JM, Paci A, Schmidt J, Mallardo D, et al. (2020) Systemic short chain fatty acids limit antitumor effect of CTLA-4 blockade in hosts with cancer. Nat Commun 11: 2168. [Crossref]

30. Jacobasch G, Dongowski G, Florian S, Müller-Schmehl K, Raab B, et al. (2008) Pectin does not inhibit intestinal carcinogenesis in APC-deficient Min/+ mice. J Agric Food Chem 56: 1501-1510. [Crossref]

31. 31.Ohara T, Suzutani T (2018) Intake of Bifidobacterium longum (BB536) and FructoOligosaccharides (FOS) prevents colorectal carcinogenesis. Euroasian J HepatoGastroenterology 8: 11-17. [Crossref]

32. Ohara T, Mori T (2019) Antiproliferative effects of short-chain fatty acids on human colorectal cancer cells via gene expression inhibition. Anticancer Res 39: 4659-4666. [Crossref]

Copyright: (C2021 Ohara T. This is an open-access article distributed under the terms of the Creative Commons Attribution License, which permits unrestricted use, distribution, and reproduction in any medium, provided the original author and source are credited. 